\title{
Photosynthesis and physiology responses of paired near-isogenic lines in waxy maize (Zea mays L.) to nicosulfuron
}

\author{
J. WANG, X.M. ZHONG, X.L. LV, Z.S. SHI, and F.H. LI \\ Department of Agronomy, Shenyang Agricultural University, Shenyang, Liaoning - 110866, China
}

\begin{abstract}
Nicosulfuron is a post-emergence herbicide used for weed control in fields of maize (Zea mays L.). We used a pair of nearly isogenic inbred lines, SN509-R (nicosulfuron-resistant) and SN509-S (nicosulfuron-sensitive), to study the effect of nicosulfuron on waxy maize seedling. After the nicosulfuron treatment, net photosynthetic rate, stomatal conductance, transpiration rate, leaf maximum photochemical efficiency of PSII, photochemical quenching of chlorophyll fluorescence, and the actual photochemical efficiency of PSII were significantly lower in SN509-S than those of SN509-R, contrary to intercellular $\mathrm{CO}_{2}$ concentration, stomatal limitation, and nonphotochemical quenching. Compared to SN509-R, antioxidant enzyme activities in SN509-S decreased significantly in response to the nicosulfuron treatment, while SN509-S exhibited an increased malondialdehyde content, which was associated with lower antioxidant enzyme activities. These results collectively suggest that the nicosulfuron-resistance mechanism was associated with photosynthetic rate, reactive oxygen species metabolism, and protective mechanisms.
\end{abstract}

Additional key words: antioxidant enzymes; chlorophyll florescence; nicosulfuron; photosynthesis; waxy maize.

\section{Introduction}

Nicosulfuron [2-[(4,6-dimethoxypyrimidin-2-ylcarbamoyl) sulfamoyl]- $N, N$-dimethylnicotinamide] is an effective, broad-spectrum, inner-absorption conducting sulfonylurea herbicide that is mainly used for the control of annual weeds and broadleaf weed species in maize production (Stall and Bewick 1992, Williams and Harvey 2000). Nicosulfuron residues in soils and rivers are degraded by hydrolysis and microbial activity, so the toxicity of nicosulfuron has a minor effect on the next crop (Wang et al. 2011). The effectiveness of nicosulfuron makes up for the paucity of post-emergence herbicides in corn, and it has been also important for the development of the herbicide industry in China.

The differences in susceptibility of weeds and crops to nicosulfuron explain its ability to control the growth of weeds effectively. Nicosulfuron selectively kills weeds, while causing minimal harm to crops (Dobbels and Kapusta 1993, Kapusta et al. 1995). Nicosulfuron is a sulfonylurea herbicide that inhibits the activity of acetolactate synthase (ALS), reduces the synthesis of branched chain amino acids, and kills weeds (Ray 1984). By contrast, nicosulfuron can be degraded into inactive substances and can lose its activity when it is combined with glucose in maize (Pataky et al. 2008, Meyer et al. 2010).

Recent nicosulfuron studies have concentrated on the degradation of nicosulfuron residue in soil and its environmental impacts, but a few studies related to plant photosystem damage have been reported. Some studies have indicated that nicosulfuron can reduce chlorophyll (Chl) contents and photosynthesis, thereby inhibiting plant growth (Saladin et al. 2003, Belgers et al. 2007, Bigot et al. 2007, Macedo et al. 2008, Hussain et al. 2010). Herbicide application damages the photosynthetic apparatus within the PSI and PSII, thus reducing the maximum photochemical efficiency of PSII $\left(\mathrm{F}_{\mathrm{v}} / \mathrm{F}_{\mathrm{m}}\right)$, the photochemical quenching coefficient $\left(\mathrm{q}_{\mathrm{p}}\right)$, and the

Received 14 March 2017, accepted 17 July 2017, published as online-first 13 April 2018.

${ }^{+}$Corresponding author; phone: +86 024 88487135; e-mail: lifenghai@126.com

Abbreviations: APX - ascorbate peroxidase; CAT - catalase; Chl - chlorophyll $; C_{\mathrm{i}}$ - intercellular $\mathrm{CO}_{2}$ concentration; DAT - days after herbicide treatment; ETR - electron transport rate; $\mathrm{F}_{0}$ - minimal fluorescence yield of the dark-adapted state; $\mathrm{F}_{\mathrm{m}}$ - maximal fluorescence yield of the dark-adapted state; $\mathrm{F}_{0}{ }^{\prime}$ - minimal fluorescence yield of the light-adapted state; $\mathrm{F}_{\mathrm{m}}{ }^{\prime}$ - maximal fluorescence yield of the lightadapted state; $\mathrm{F}_{\mathrm{v}}$ - variable fluorescence; $\mathrm{F}_{\mathrm{v}} / \mathrm{F}_{\mathrm{m}}$ - maximal quantum yield of PSII photochemistry; $g_{\mathrm{s}}$ - stomatal conductance; $\mathrm{L}_{\mathrm{s}}$ - stomatal limitation; MDA - malondialdehyde; NPQ - nonphotochemical quenching; NILs - nearly-isogenic lines; NBT - nitroblue tetrazolium chloride; $P_{\mathrm{N}}-$ net photosynthetic rate; $\mathrm{POD}$ - peroxidase; $\mathrm{q}_{\mathrm{P}}-$ photochemical quenching coefficient; ROS - reactive oxygen species; SOD - superoxide dismutase; $\Phi_{\text {PSII }}$ - effective quantum yield of PSII photochemistry.

Acknowledgements: This work was supported by the National Science and Technology Support Project (2014215031) and Cultivation Plan for Youth Agricultural Science and Technology Innovative Talents of Liaoning Province (2015041). 
quantum yield of PSII electron transport ( $\Phi_{\text {PSII }}$ ) (Kaňa et al. 2004, Tan et al. 2012, Hu et al. 2014, Debona et al. 2016). This is due to the excessive reactive oxygen species (ROS) which are produced by photosynthesis under the stress conditions. The $\mathrm{Q}_{\mathrm{A}}$ and primary electron acceptor of PSII are reduced, leading to the direct attack of ROS on the photochemical reaction center of PSII (Vass et al. 1992). However, with the constant evolution of plants, herbicide toxicity can be minimized by self-defense mechanisms. One of these protective mechanisms is the antioxidant system, an important plant defense mechanism. It can be combined with a variety of enzymes to remove excessive ROS so that the PSI and PSII are not affected (Jiang and Yang 2009). Hwang et al. (2004) used a superoxide dismutase (SOD) inhibitor to treat leaves of chilling-resistant spinach, which reduced the activity of the PSI by $50 \%$. At the same time, a large number of studies have confirmed that the antioxidant system plays a key role

\section{Materials and methods}

Experimental design: The experiment was designed at the south farm of Shenyang Agricultural University $\left(41^{\circ} 49^{\prime} \mathrm{N}, 123^{\circ} 34^{\prime} \mathrm{E}\right)$, within the north temperate zone, with a monsoon-affected semi-humid continental climate. The fundamental nutrient content of the tested soil was $26.79 \mathrm{~g}$ (organic matter) $\mathrm{kg}^{-1}, 2.45 \mathrm{~g}$ (total nitrogen) $\mathrm{kg}^{-1}$, $110.75 \mathrm{mg}$ (alkaline-hydrolyzed nitrogen) $\mathrm{kg}^{-1}, 11.09 \mathrm{mg}$ (available phosphorous) $\mathrm{kg}^{-1}$, and $105.74 \mathrm{mg}$ (available potassium) $\mathrm{kg}^{-1}$. A pair of NILs, SN509-R and SN509-S, were developed by the Institute of Speciality Corn of Shenyang Agricultural University. The SN509-R line grew normally after being sprayed with nicosulfuron. By contrast, nicosulfuron inhibits the growth of the SN509-S inbred line, which ultimately causes the plant to die. A split-plot experimental design was used with the nicosulfuron treatment defining the main plots and inbred lines within subplots. The row length of one plot was $6 \mathrm{~m}$, and the row width was $0.6 \mathrm{~m}$. We set up eight rows in each plot, with each plot measuring $28.8 \mathrm{~m}^{2}$ in area.

Pesticide treatments: In 2015, an experiment was conducted in an incubator maintained at $27^{\circ} \mathrm{C}$ with a relative humidity of $85 \%$. Uniformly sized seeds of two inbred lines were sown after being rinsing with a small volume of distilled water in culture dishes. After $7 \mathrm{~d}$, uniformly sized buds $(0.01 \mathrm{~m})$ were transferred to the new culture dishes with filter paper. Following nicosulfuron concentrations: $0 \mathrm{mg} \mathrm{kg}^{-1}$ (control), 8, 40, 80, 120, 160, 240, 320, and $400 \mathrm{mg} \mathrm{kg}^{-1}$ were applied to each of the cultures to screen the resistance of SN509-R and SN509-S under a wide range of herbicide concentrations. Fifty buds of each line were evenly spread into culture dishes, with three replicates. After $2 \mathrm{~d}$, buds were transferred to the field, and the survival rate was investigated at the five-leaf stage. This screening revealed that when the concentration of in the protection of the PSI by scavenging hydroxyl radicals, superoxide, and hydrogen peroxide (Jakob and Heber 1996, Sonoike 1996, Aroca et al. 2001, Tjus et al. 2001).

The effects of nicosulfuron on photosynthesis and antioxidant enzyme activities in waxy maize leaves have not been reported yet. Accordingly, we investigated the effects of nicosulfuron on the net photosynthetic rate, fluorescence characteristics, and antioxidant enzymes in a pair of nicosulfuron-resistant and nicosulfuron-sensitive nearly-isogenic lines (NILs) of maize, SN509-R and SN509-S. We selected these paired NILs in order to minimize effects caused by differences in genetic background. Our study helped us further understand the mechanism of physiological defense in different sensitive inbred lines, which provides a strong theoretical basis for the innovation, screening, and conservation of maize germplasm resources that are resistant to nicosulfuron.

nicosulfuron was $80 \mathrm{mg} \mathrm{kg}^{-1}$, SN509-R plants were able to attain normal growth via self-defense mechanisms, while SN509-S plants wilted or died (Table 1). In 2016, an experiment was conducted in a field. The maize seedlings were treated with nicosulfuron at the five-leaf stage using a laboratory pot sprayer equipped with a nozzle. The nicosulfuron concentration was maintained at $80 \mathrm{mg} \mathrm{kg}^{-1}$ to investigate effects on photosynthetic and physiological parameters and antioxidant enzyme activities of maize seedlings. Because the seedlings of SN509-S either died or wilted after $15 \mathrm{~d}$ after herbicide treatment (DAT), data were determined every $2 \mathrm{~d}$ after 0 DAT.

Gas exchange: The $L I-6400$ portable optical instrument (LI-COR Biosciences Inc., Lincoln, NE, USA) was used to measure several parameters at a light intensity of 1,200 \pm $50 \mu \mathrm{mol}$ (photon) $\mathrm{m}^{-2} \mathrm{~s}^{-1}, \mathrm{CO}_{2}$ concentration of $360 \pm$ $20 \mu \mathrm{mol} \mathrm{mol}{ }^{-1}$, and air temperature of $25 \pm 1{ }^{\circ} \mathrm{C}$, including the net photosynthetic rate $\left(P_{\mathrm{N}}\right)$, stomatal conductance $\left(g_{\mathrm{s}}\right)$, intercellular $\mathrm{CO}_{2}$ concentrations $\left(C_{\mathrm{i}}\right)$, and transpiration rate $(E)$.

Chlorophyll (Chl) fluorescence parameters were analyzed with a $P A M-2500$ pulse modulated fluorometer (Walz, Germany) connected to a computer with the data acquisition software PAMwin3. Prior to the measurements, the leaves were adapted to darkness. The minimal fluorescence yield of the dark-adapted state $\left(\mathrm{F}_{0}\right)$ was determined using a very low modulated light $[<0.1 \mu \mathrm{mol}$ (photon) $\left.\mathrm{m}^{-2} \mathrm{~s}^{-1}\right]$. The maximal fluorescence yield of the lightadapted state $\left(\mathrm{F}_{\mathrm{m}}\right)$ and maximal quantum yield of PSII photochemistry $\left(\mathrm{F}_{\mathrm{v}} / \mathrm{F}_{\mathrm{m}}\right)$ were determined by using a 600 ms saturated light pulse. Then, the leaves were illuminated with an actinic light $\left[800 \mu \mathrm{mol}\left(\right.\right.$ photon) $\left.\mathrm{m}^{-2} \mathrm{~s}^{-1}\right]$ in order to determine the steady state $\left(\mathrm{F}_{\mathrm{s}}\right)$ and the maximal fluorescence yield of the light-adapted state $\left(\mathrm{F}_{\mathrm{m}}{ }^{\prime}\right)$. 
Table 1. Effect of nicosulfuron on germination rate of waxy maize seed of SN509-R and SN509-S. * - differences under different days after herbicide treatment at $P<0.05$, according to the least significant difference (LSD) test. CK - Control.

\begin{tabular}{|c|c|c|c|c|c|c|c|c|}
\hline \multirow{2}{*}{$\begin{array}{l}\text { Spaying } \\
\text { concentration } \\
{\left[\mathrm{mg} \mathrm{k}^{-1}\right]}\end{array}$} & \multicolumn{3}{|c|}{ Germination percentage } & \multicolumn{5}{|c|}{ Survival rate after germination } \\
\hline & SN509-R & Than CK [\%] & SN509-S & Than CK [\% & SN509-R & Than CK [\%] & SN509-S & Than CK [\%] \\
\hline 0 & 91.3 & - & 91.5 & - & 100 & - & 100 & - \\
\hline 8 & 90.6 & -0.8 & 8.8 & $-90.4^{*}$ & 100 & 0.0 & 0.0 & $-100.0^{*}$ \\
\hline 40 & 89.2 & -2.4 & 2.5 & $-97.3^{*}$ & 100 & 0.0 & 0.0 & $-100.0^{*}$ \\
\hline 80 & 88.5 & -3.2 & - & & 99.1 & -0.9 & - & \\
\hline 120 & 79.2 & $-13.3^{*}$ & - & & 94.2 & $-5.8^{*}$ & - & \\
\hline 160 & 66.4 & $-27.3^{*}$ & - & & 82.9 & $-17.1^{*}$ & - & \\
\hline 240 & 18.8 & $-79.5^{*}$ & - & & 14.7 & $-85.3^{*}$ & - & \\
\hline 320 & 7.2 & $-92.1^{*}$ & - & & 1.8 & $-98.2^{*}$ & - & \\
\hline 400 & 3.8 & $-95.8^{*}$ & - & & 0.4 & $-99.6^{*}$ & - & \\
\hline
\end{tabular}

The following Chl fluorescence parameters were collected: the maximal quantum yield of PSII photochemistry $\left(\mathrm{F}_{\mathrm{v}} / \mathrm{F}_{\mathrm{m}}\right)$, calculated according to van Kooten and Snel (1990); the effective quantum yield of PSII photochemistry $\left(\Phi_{\mathrm{PSII}}\right)$ and electron transport rate $(\mathrm{ETR})$, calculated according to Genty et al. (1989); the photochemical quenching coefficient $\left(\mathrm{q}_{\mathrm{p}}\right)$, calculated as $\mathrm{q}_{\mathrm{P}}=$ $\left(\mathrm{F}_{\mathrm{m}}-\mathrm{F}_{\mathrm{s}}\right) /\left(\mathrm{F}_{\mathrm{m}}-\mathrm{F}_{0}\right)$; nonphotochemical quenching (NPQ), calculated as NPQ $=\left(\mathrm{F}_{\mathrm{m}}-\mathrm{F}_{\mathrm{m}}{ }^{\prime}\right) / \mathrm{F}_{\mathrm{m}}{ }^{\prime}$.

Assay of antioxidant enzyme activities (superoxide dismutase, peroxidase, catalase, and ascorbate peroxidase): After the nicosulfuron treatment, the seedling leaves were sampled, frozen in liquid nitrogen, and then stored at $-80^{\circ} \mathrm{C}$ until subsequent analysis. Enzyme activities were measured spectrophotometrically and absorbances were recorded by a UNICO ${ }^{\mathrm{TM}} U V-2000$ spectrophotometer ( $U V$-2000, UNICO, USA).

Enzyme extraction: Enzymes were extracted by grinding $0.5 \mathrm{~g}$ of leaf samples in $5 \mathrm{ml}$ of phosphate buffer $(\mathrm{pH} 7.5)$ containing $0.05 \mathrm{mM}$ EDTA. The homogenate was centrifuged at $10,000 \times g$ at $4^{\circ} \mathrm{C}$ for $20 \mathrm{~min}$ and the supernatant was collected for measurement of enzyme activities.

Superoxide dismutase (SOD, EC 1.15.1.1) activity: The method described by Giannopolitis and Ries (1977) was used to measure the SOD activity. The $3 \mathrm{ml}$ of reaction mixture contained $100 \mathrm{mM}$ phosphate buffer ( $\mathrm{pH} 7.8$ ), $3.0 \mathrm{mM}$ EDTA, $200 \mathrm{mM}$ methionine, $2.25 \mathrm{mM}$ nitroblue tetrazolium chloride (NBT), $60 \mu \mathrm{M}$ riboflavin, and $1.5 \mathrm{M}$ sodium carbonate. The photoreduction of NBT was measured by recording absorbance at $560 \mathrm{~nm}$. The enzyme activity was caculated as $50 \%$ inhibition expressed in unit $\mathrm{g}^{-1}$ (fresh mass, FM). One unit of SOD activity was defined as the enzyme activity that inhibited the photoreduction of NBT to purple formazan by $50 \%$.

Peroxidase (POD, EC 1.11.1.7) activity: The method described by Cakmak and Marschner (1992) was used to determine guaiacol peroxidase activity. The catalyzed reaction system consisted of $1.0 \mathrm{ml}$ of phosphate buffer (100 mM, pH 6.1), $0.5 \mathrm{ml}$ of guaiacol, $0.5 \mathrm{ml}$ of $\mathrm{H}_{2} \mathrm{O}_{2}$, and $0.1 \mathrm{ml}$ of enzyme extract. Changes in the absorbance of the reaction solution described above at $470 \mathrm{~nm}$ (extinction coefficient $=26 \mathrm{mM}^{-1} \mathrm{~cm}^{-1}$ ) caused by the formation of tetraguaicol were recorded for $3 \mathrm{~min}$. The enzyme activity was calculated and expressed in $\mu \mathrm{mol}$ (guaicol reduced) $\min ^{-1} \mathrm{~g}^{-1}(\mathrm{FM})$.

Catalase (CAT, EC 1.11.1.6) activity: Catalase activity was assayed according to the method described by Aebi (1984). A decrease in the absorbance due to the disappearance of $\mathrm{H}_{2} \mathrm{O}_{2}$ was measured at $240 \mathrm{~nm}$ (extinction coefficient $=0.036 \mathrm{mM}^{-1} \mathrm{~cm}^{-1}$ ). The catalyzed reaction system consisted of $100 \mathrm{mM}$ phosphate buffer $(\mathrm{pH} 7.0)$, $10 \mathrm{mM} \mathrm{H}_{2} \mathrm{O}_{2}$, and enzyme extract. The enzyme activity was expressed in $\mu$ mol $\left(\mathrm{H}_{2} \mathrm{O}_{2}\right.$ oxidised $) \mathrm{min}^{-1} \mathrm{~g}^{-1}(\mathrm{FM})$.

Ascorbate peroxidase (APX, EC 1.11.1.11) activity: The reaction mixture contained $50 \mathrm{mM}$ phosphate buffer (pH 7.0), $0.3 \mathrm{mM}$ ascorbate, $0.1 \mathrm{mM}$ EDTA, $0.06 \mathrm{mM}$ $\mathrm{H}_{2} \mathrm{O}_{2}$, and enzyme extract. The decrease in the absorbance caused by the reduction of ascorbate concentration was measured at $290 \mathrm{~nm}$, and the extinction coefficient $\left(2.8 \mathrm{mM}^{-1} \mathrm{~cm}^{-1}\right)$ was used to calculate the enzyme activity. The enzyme activity of APX was expressed in $\mu \mathrm{mol}$ (product) $\mathrm{min}^{-1} \mathrm{~g}^{-1}$ (FM) (Nakano and Asada 1981).

Malondialdehyde (MDA) content: After the nicosulfuron treatment, the seedling leaves were sampled and placed in liquid nitrogen, and then stored at $-80^{\circ} \mathrm{C}$ until analyses were performed. The thiobarbituric acid method was used to determine the MDA content of the samples (Heath and Packer 1968). MDA was extracted by grinding $0.5 \mathrm{~g}$ of leaf samples in $5 \mathrm{ml}$ of phosphate buffer $(0.05 \mathrm{mM}$, $\mathrm{pH} 7.8$ ). The homogenate was centrifuged at $4,500 \times g$ for $10 \mathrm{~min}$ and the supernatant was collected for measurement of MDA. The $2 \mathrm{ml}$ of extract and $3 \mathrm{ml}$ of $0.5 \%$ thiobarbituric acid (TBA) containing 5\% trichloroacetic acid (TCA) were boiled for $10 \mathrm{~min}$, and the solution was 
cooled to room temperature. The mixture was then centrifuged at $4,500 \times g$ for $10 \mathrm{~min}$. The absorbance of the supernatant was recored at 450, 532, and $600 \mathrm{~nm}$ with a $U N I C O^{\text {TM }} U V-2000$ spectrophotometer $(U V-2000$, $U N I C O$, USA). MDA was expressed as nmol $\mathrm{g}^{-1}(\mathrm{FM})$, and the extinction coefficient $\left(155 \mathrm{mM}^{-1} \mathrm{~cm}^{-1}\right)$ was used to calculate lipid peroxidation.

Proline content: Samples of $0.5 \mathrm{~g}$ from leaves were homogenized with $5 \mathrm{ml}$ of 3\% sulfosalicylic in a boiling water bath for $10 \mathrm{~min}$, and then the homogenate was filtered through filter paper. A reaction mixture containing $2 \mathrm{ml}$ of glacialacetic acid, $3 \mathrm{ml}$ of acid-ninhydrin, and $2 \mathrm{ml}$ of extract was boiled in a water bath for $40 \mathrm{~min}$. After

\section{Results}

$\boldsymbol{P}_{\mathrm{N}}$ : Nicosulfuron decreased $P_{\mathrm{N}}$ differently in the two inbred lines (Fig.1). Compared to 0 DAT, nicosulfuron significantly decreased the $P_{\mathrm{N}}$ values of SN509-R at 5, 7, and 9 DAT by up to 5.0, 3.0, and $11.0 \%$, respectively. Nicosulfuron also significantly reduced the $P_{\mathrm{N}}$ values of SN509-S at 1, 3, 5, 7, and 9 DAT by up to 3.3, 3.9, 28.1, 99.6 , and $99.8 \%$, respectively. In general, the effect of nicosulfuron on $P_{\mathrm{N}}$ was much higher in SN509-S than that in SN509-R. After 1 DAT, the $P_{\mathrm{N}}$ value of SN509-R was 28.31-24.23 $\mu \mathrm{mol} \mathrm{m} \mathrm{m}^{-2} \mathrm{~s}^{-1}$, with an average of $26.62 \mu \mathrm{mol}$ $\mathrm{m}^{-2} \mathrm{~s}^{-1}$; in contrast, the $P_{\mathrm{N}}$ value of SN509-S was 0.06-26.64 $\mu \mathrm{mol} \mathrm{m} \mathrm{m}^{-2} \mathrm{~s}^{-1}$, with an average of only 14.62 $\mu \mathrm{mol} \mathrm{m} \mathrm{m}^{-2} \mathrm{~s}^{-1}$. The average $P_{\mathrm{N}}$ of SN509-R was $45.1 \%$ higher than that of SN509-S. Compared to the SN509-S line, the SN509-R line maintained a higher photosynthetic capacity after spraying with nicosulfuron and completed its normal growth and development.

$\boldsymbol{g}_{\mathrm{s}}, \boldsymbol{E}, \mathrm{L}_{\mathrm{s}}$, and $\boldsymbol{C}_{\mathrm{i}}$ : Nicosulfuron had little effect on the photosynthetic parameters of SN509-R, in contrast to those of SN509-S. The $g_{\mathrm{s}}$ of SN509-R was first reduced, and then increased by each day following treatments (Table 2), while the $g_{\mathrm{s}}$ of SN509-S continued to decline after 5 DAT. Compared to 0 DAT, nicosulfuron significantly decreased the $g_{\text {s }}$ of SN509-S by up to 27.8, 94.4 , and $94.4 \%$ by 5,7 , and 9 DAT, respectively. Nicosulfuron had no significant effect on the $C_{\mathrm{i}}, E$, and $\mathrm{L}_{\mathrm{s}}$ of SN509-R, in contrast to those of SN509-S. After 9 DAT, the $C_{\mathrm{i}}$ and $\mathrm{L}_{\mathrm{s}}$ of $\mathrm{SN} 509-\mathrm{S}$ reached their maximum values of $321.74 \mu \mathrm{mol}\left(\mathrm{CO}_{2}\right) \mathrm{mol}^{-1}$ and 0.87 , respectively, which were was 171.8 and $248 \%$ higher than those at 0 DAT, respectively. The $E$ of SN509-S reached a minimum value of $0.19 \mathrm{mmol}\left(\mathrm{H}_{2} \mathrm{O}\right) \mathrm{m}^{-2} \mathrm{~s}^{-1}$, which was $95.4 \%$ lower than that at 0 DAT. The photosynthetic parameters were compared between the two inbred lines: compared to SN509-R, the nicosulfuron treatment significantly reduced the $g_{\mathrm{s}}$ and $E$ of SN509-S by 40.7 and $46.9 \%$, on average, respectively. The $C_{\mathrm{i}}$ and $\mathrm{L}_{\mathrm{s}}$ of SN509-S were remarkably higher than those of SN509-R. Our study showed that the $\mathrm{L}_{\mathrm{s}}$ might be the main reason for the decline of $P_{\mathrm{N}}$ in cooling, the solution was mixed with $5 \mathrm{ml}$ of methylbenzene and stirred well. The absorbance of the red methylbenzene supernatant was measured at $520 \mathrm{~nm}$ with a $U N I C O^{\text {тм }} U V-2000$ spectrophotometer (UNICO, USA). Proline content was expressed as $\mu \mathrm{g} \mathrm{g}^{-1}(\mathrm{FM})$.

Data analysis: Microsoft Excel and SigmaPlot 12.5 were used for data processing and mapping, and each reported data point is the mean \pm standard error (SE) of three replicates combined in the three experimental repeats. SPSS version 12.0 (SPSS Inc., Chicago, IL, USA) was used to conduct analysis of variance (ANOVA), and comparisons among mean values were made by least significant difference (LSD) test at a $P<0.05$ significance threshold.

SN509-S, and it was also the main response of SN509-S to the nicosulfuron treatment.

$\mathbf{F}_{\mathbf{v}} / \mathbf{F}_{\mathbf{m}}$ : represents the photochemical conversion efficiency and potential activity in plant leaves. Nicosulfuron had little effect on the $\mathrm{F}_{\mathrm{v}} / \mathrm{F}_{\mathrm{m}}$ of SN509-R, while $\mathrm{F}_{\mathrm{v}} / \mathrm{F}_{\mathrm{m}}$ of SN509-S declined (Fig. $2 A$ ). Compared to 0 DAT, $\mathrm{F}_{\mathrm{v}} / \mathrm{F}_{\mathrm{m}}$ of SN509-S declined by $0.7,8.5,32.4$, and $27.6 \%$ by $3,5,7$, and 9 DAT, respectively; $\mathrm{F}_{\mathrm{v}} / \mathrm{F}_{\mathrm{m}}$ of SN509-R increased by an average of $1.5 \%$ from 3 DAT to 9 DAT. Additionally, the $\mathrm{F}_{\mathrm{v}} / \mathrm{F}_{\mathrm{m}}$ of SN509-R was significantly higher than that of SN509-S at $3,5,7,9$ DAT, with increases of 2.3, 3.9, 29.6, and 29.1\%, respectively. The $\mathrm{F}_{\mathrm{v}} / \mathrm{F}_{\mathrm{m}}$ indicated that the SN509-R had a greater capacity to adapt to herbicide stress.

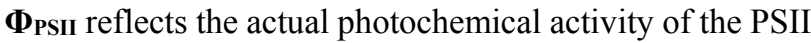
(Govindjee 2002). The $\Phi_{\text {PSII }}$ values of the inbred lines had

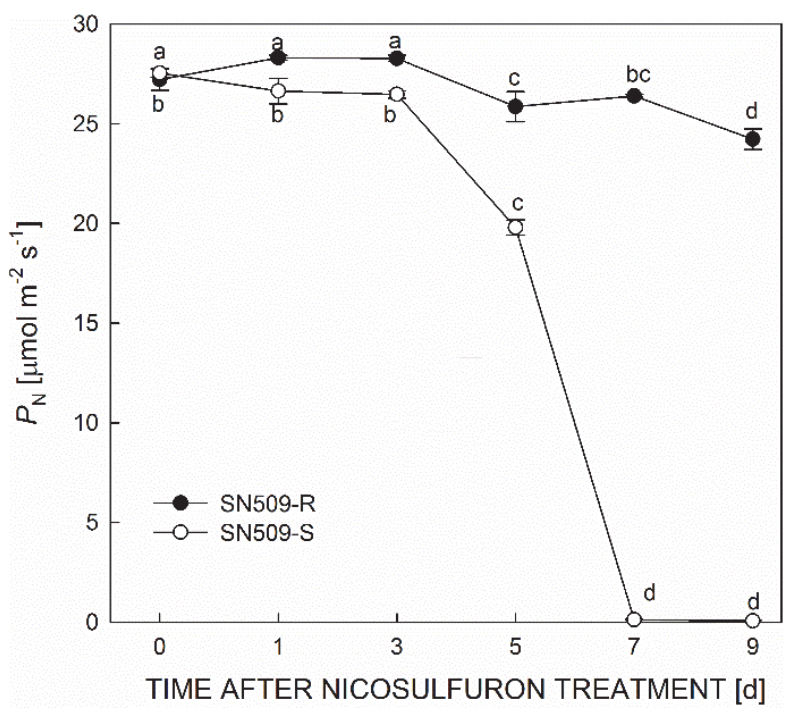

Fig. 1. Effects of nicosulfuron on the net photosynthetic rate $\left(P_{\mathrm{N}}\right)$ in leaves of maize seedlings. Vertical bars represent the SE $(n=5)$. Small letters indicate differences between values obtained on different days after nicosulfuron treatment $(P<0.05)$ according to a least significant difference (LSD) test. 


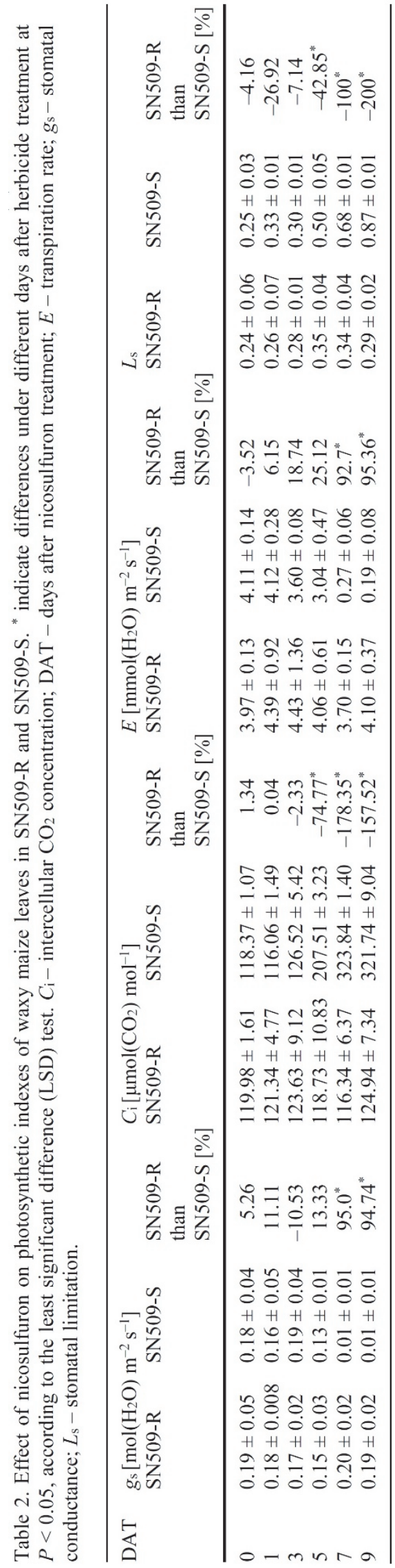

different responses to nicosulfuron over time (Fig. 2B). $\Phi_{\text {PSII }}$ of SN509-S was reduced, while nicosulfuron had little effect on $\Phi_{\mathrm{PSII}}$ of SN509-R. Except for 3 DAT, the $\Phi_{\text {PSII }}$ of SN509-R was significantly higher than that of SN509-S at 1, 5, 7, and 9 DAT, with increases of 16.6, $58.5,71.3$, and $64.8 \%$, respectively. This suggested that SN509-R resisted to injury caused by herbicide through its own regulatory mechanisms.

ETR reflects the efficiency of the apparent electron transfer under the actual light intensity, and it has a strong linear relationship with the photosynthetic rate (Zhong et al. 2014). In SN509-R, ETR was first reduced, and then increased with the exposure time (Fig. 2C), while ETR was reduced in SN509-S throughout. The average ETR of SN509-R was $39.5 \%$ higher than that of SN509-S. The reduction of ETR was a consistent explanation for the decrease of $P_{\mathrm{N}}$ in SN509-S.

$\mathbf{q}_{\mathbf{P}}$ is commonly used to determine the openness of the PSII. Nicosulfuron caused little change in $\mathrm{q}_{\mathrm{P}}$ of SN509-R, while qp of SN509-S was significantly reduced (Fig. 2D). The qp of SN509-R was significantly higher than that of SN509-S. The nonphotochemical quenching coefficient (NPQ) reflects the ability to dissipate excess light energy. After being sprayed with herbicide, $\mathrm{F}_{\mathrm{v}} / \mathrm{F}_{\mathrm{m}}$, $\Phi_{\text {PSII }}$, ETR, and $\mathrm{q}_{\mathrm{P}}$ decreased in leaves of SN509-S. In contrast, NPQ was enhanced (Fig. 2E). Nonradiative energy dissipation appeared to play a key role in the reduction of PSII activity.

Antioxidant enzyme activities: The antioxidant enzyme system plays an important role in scavenging ROS in the PSI and PSII (Jiang et al. 2009). Our experiment showed that nicosulfuron treatment induced significant decreases in SOD enzyme activity in two inbred lines at each sampling time. SOD activity of SN509-S was much lower than that of SN509-R. After herbicide treatment, the POD activity of SN509-R increased as the exposure time increased, while the POD activity of SN509-S was reduced as the exposure time increased. The average POD activity of SN509-R was $49.9 \%$ higher than that of SN509-S. The CAT activity in the two inbred lines was significantly reduced over the exposure time. The average CAT activity of SN509-S was $16.0 \%$ lower than that of SN509-R. After 3 DAT, the APX activity of the two inbred lines reached its maximum values, and then declined. After 9 DAT, the APX activity of SN509-R increased slightly, and was $14.5 \%$ higher than that of SN509-S (Fig. 3).

MDA content: After 5 DAT, the MDA content of SN509-R reached its maximum value, and then decreased, while the MDA content of SN509-S increased with the exposure time. Compared to SN509-R, the MDA content of SN509$\mathrm{S}$ significantly increased by $28.9,65.6$, and $62.9 \%$, respectively (Fig. 4A). 


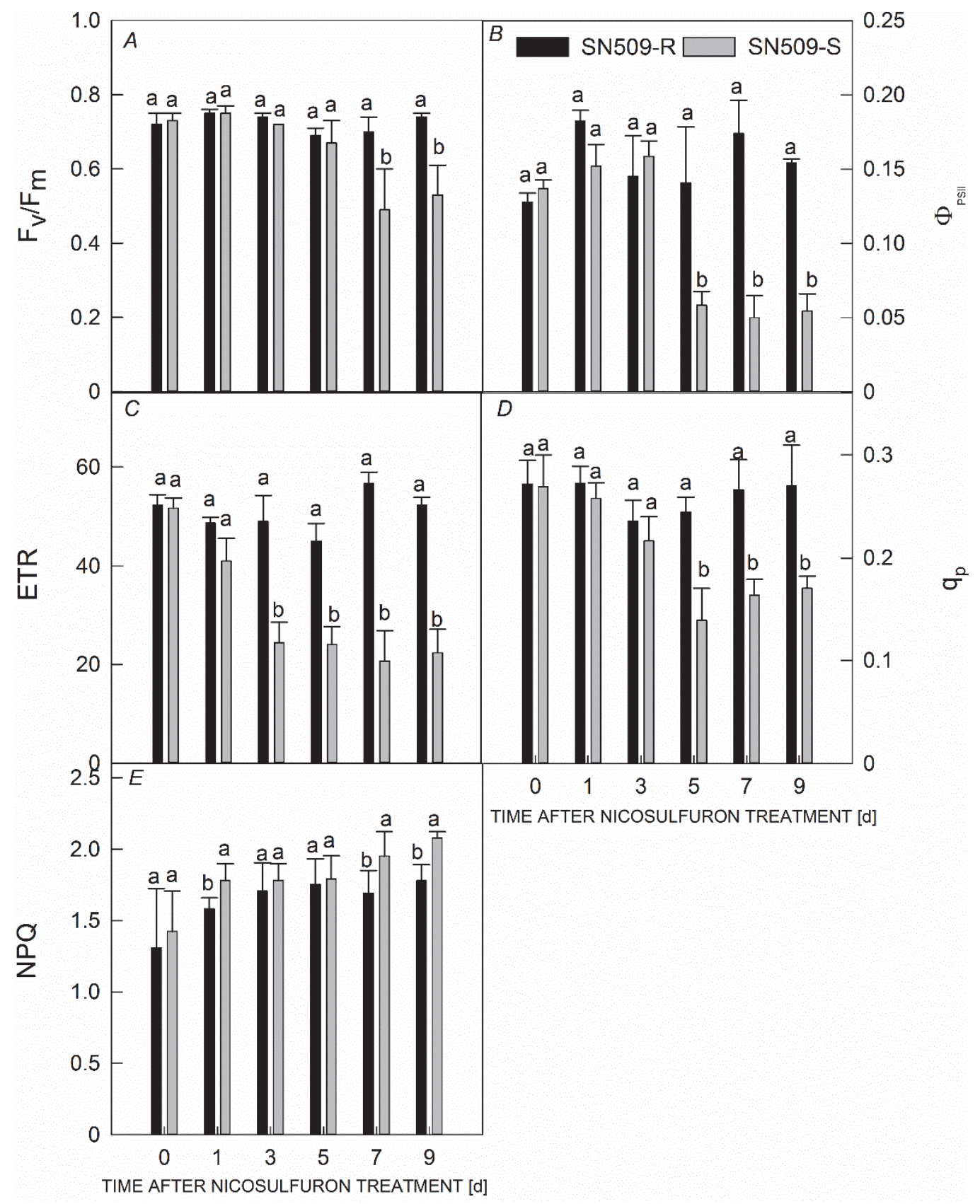

Fig. 2. Effects of nicosulfuron on leaf maximum photochemical efficiency of PSII ( $\left.\mathrm{F}_{\mathrm{v}} / \mathrm{F}_{\mathrm{m}} ; A\right)$, actual photochemical efficiency of PSII $(\Phi \mathrm{PSI} ; B)$, electron transport rate (ETR; $C$ ), photochemical quenching $\left(\mathrm{q}_{\mathrm{p}} ; D\right)$, and nonphotochemical quenching $(\mathrm{NPQ} ; E)$ in leaves of SN509-R and SN509-S. Vertical bars represent the SE $(n=5)$. Small letters indicate differences in values obtained on different days after nicosulfuron treatment $(P<0.05)$ according to a least significant difference (LSD) test.

Proline content: After the herbicide treatment, the proline content of the two inbred lines increased, and the content of SN509-R increased significantly (Fig. 4B). Compared to SN509-S, the proline content of SN509-R increased by

\section{Discussion}

Both development and popularization of herbicides were accompanied with precision agriculture and benefited
$18.9,26.4,22.3$, and $34.8 \%$ at $3,5,7$, and 9 DAT, respectively. This suggests that the increase in proline was related to the resistance of SN509-R to nicosulfuron treatment.

agriculture. Accordingly, the total application area of herbicides has rapidly expanded since the 1970s in Europe 
and America (Wu et al. 2004). During the past 20-30 years, the application of herbicides in America and Canada has increased 3- to 5-fold (Freemark and Boutin 1994). Since the 1990s, the herbicide industry in China has entered a period of accelerated development and the proportion of herbicides, accounting for three types of pesticides, has increased linearly. Nicosulfuron in agricultural production has been widely used as a postemergence herbicide in maize. Many studies have demonstrated that maize cultivars differ in their sensitivity to nicosulfuron (Eberline et al. 1989, Wang et al. 2016). Therefore, the harm that nicosulfuron causes to maize crops should be further studied in order to evaluate its impact on different corn varieties, a crucial issue in maize production that urgently needs to be addressed.

Herbicide-induced damage to crops can be evaluated by measuring agronomic traits and physiological indexes. Many herbicides are photosynthesis inhibitors, that operate by interfering with the electron transport rate, which is significantly reduced in the thylakoid membranes of chloroplasts from plants treated with clomazone (Kaňa et al. 2004). A similar effect occurs following atrazine treatment. When atrazine binds to the D1 protein of PSII, electron transfer is blocked (Zheleva et al. 1994). Similarly, fluoroglycofen and acetochlor treatments reduce $P_{\mathrm{N}}$ and $g_{\mathrm{s}}$ in grape leaves (Bigot et al. 2007). Nicosulfuron can be absorbed by leaves and roots and can then be transported by the xylem and phloem, thus decreasing photosynthesis in leaves (Dobbels et al.1993, Wang et al. 2016). In our experiment, the NILs SN509-R and SN509-S were used to assess resistance of maize to nicosulfuron, especially, the effect of the herbicide on photosynthetic and physiological properties. Our results showed that $P_{\mathrm{N}}, \mathrm{F}_{\mathrm{v}} / \mathrm{F}_{\mathrm{m}}, \mathrm{q}_{\mathrm{P}}, \mathrm{ETR}$, and $\Phi_{\mathrm{PSII}}$ decreased significantly as the exposure time increased in SN509-S, while the photosynthetic capacity of SN509-R remained high, so as to maintain the normal growth of crops. After 7 DAT, $P_{\mathrm{N}}$ and $E$ of SN509-S significantly decreased, while $C_{\mathrm{i}}$ and $\mathrm{L}_{\mathrm{s}}$ of SN509-S significantly increased, indicating that the decrease of $P_{\mathrm{N}}$ could be mainly attributed to stomatal limitation. We inferred that the chloroplast structure of the maize seedling leaf was destroyed due to the action of nicosulfuron, leading to a reduction in the thylakoid stacking level (Liu et al. 2007, Yuan et al. 2014). Thus, the light energy conversion efficiency of the photosynthetic apparatus was affected, and the normal growth and development of the plant were inhibited.

On the chloroplast thylakoid membrane, PSI and PSII are sensitive to changes in the surrounding environments. PSII is destroyed by changes in its external environment, resulting in substantial increases in $\mathrm{F}_{0}$ (Demmig et al. 1987). Nicosulfuron has significant effects on Chl fluorescence parameters in SN509-S. $\mathrm{F}_{\mathrm{v}} / \mathrm{F}_{\mathrm{m}}, \mathrm{q}_{\mathrm{P}}$, ETR, and
$\Phi_{\text {PSII }}$ significantly decreased, while NPQ significantly increased. Frankart et al. (2003) studied the effects of paraquat and norflurazon on Chl fluorescence parameters in Lemna minor, and found significant reductions in $\mathrm{F}_{\mathrm{v}} / \mathrm{F}_{\mathrm{m}}$, $\mathrm{q}_{\mathrm{P}}$, and $\Phi_{\mathrm{PSII}}$, but increased NPQ. Conversely, terbutryn, flumioxazin, and nicosulfuron decrease the NPQ in grape, Vicia faba, and Radix isatidis, respectively (Frankart et al. 2003, Murata et al. 2007, Yuan et al. 2014). A lower proportion of opened PSII centers results from the reduction of $\mathrm{q}_{\mathrm{P}}$. Furthermore, NPQ is involved in energy dissipation in the leaf. After the nicosulfuron treatment, NPQ of SN509-S significantly increased, and $\Phi_{\text {PSII }}$ decreased. These results suggest that the reduction in PSII activity was mainly caused by nonradiative energy dissipation.

The reduction of $P_{\mathrm{N}}$ and the photochemical efficiency of PSII are closely linked to a high concentration of ROS (Ramel et al. 2009). Many herbicides cause direct or indirect oxidative damage in plants (Qian et al. 2008, Jiang et al. 2009). The destruction of redox homeostasis causes a reduction in antioxidant enzyme activity, and these changes can be used to as an indicator of oxidative stress (Platiša et al. 2008). Many studies have indicated that antioxidant enzymes in various plants respond differently to different herbicides due to differences in treatment methods and treatment time and the point at which measurements are taken, and there are also concentration and time effects (Geoffroy et al. 2004, Yoon et al. 2011, Wang et al. 2016). SOD, POD, CAT, and APX are important antioxidant enzymes. In this study, after spraying by herbicide, SOD, CAT, and APX activities were significantly reduced in both inbred lines. However, SOD, CAT, and APX of SN509-R were higher than those of SN509-S. POD is a crucial antioxidant enzyme. A wide range of electron donors enable conversion of $\mathrm{H}_{2} \mathrm{O}_{2}$ to $\mathrm{H}_{2} \mathrm{O}$ by POD (Xue et al. 2008). Furthermore, POD also can improve the defense mechanism in plant leaves and roots exposed to chemicals and other abiotic stresses (Tarchoune et al. 2010). After herbicide treatment, the POD activity of SN509-R increased as the exposure time increased, while the POD of SN509-S decreased as the exposure time increased. The average POD activity of SN509-R was 50\% higher than that of SN509-S. Thus, the POD enzyme activity in the leaves of SN509-R showed a significantly positive correlation with the exposure time. It is possible that SN509-R could promote POD activity for protection under nicosulfuron stress. Many studies have demonstrated that membrane lipid peroxidation leads to the accumulation of MDA, and herbicide treatment causes the accumulation of MDA (Hassan and Nemat Alla 2005, Wu et al. 2010). In this study, the MDA content of SN509$\mathrm{S}$ increased as the exposure time increased, while the content of SN509-R was significantly lower than that of SN509-S. These findings suggested that oxidative stress 


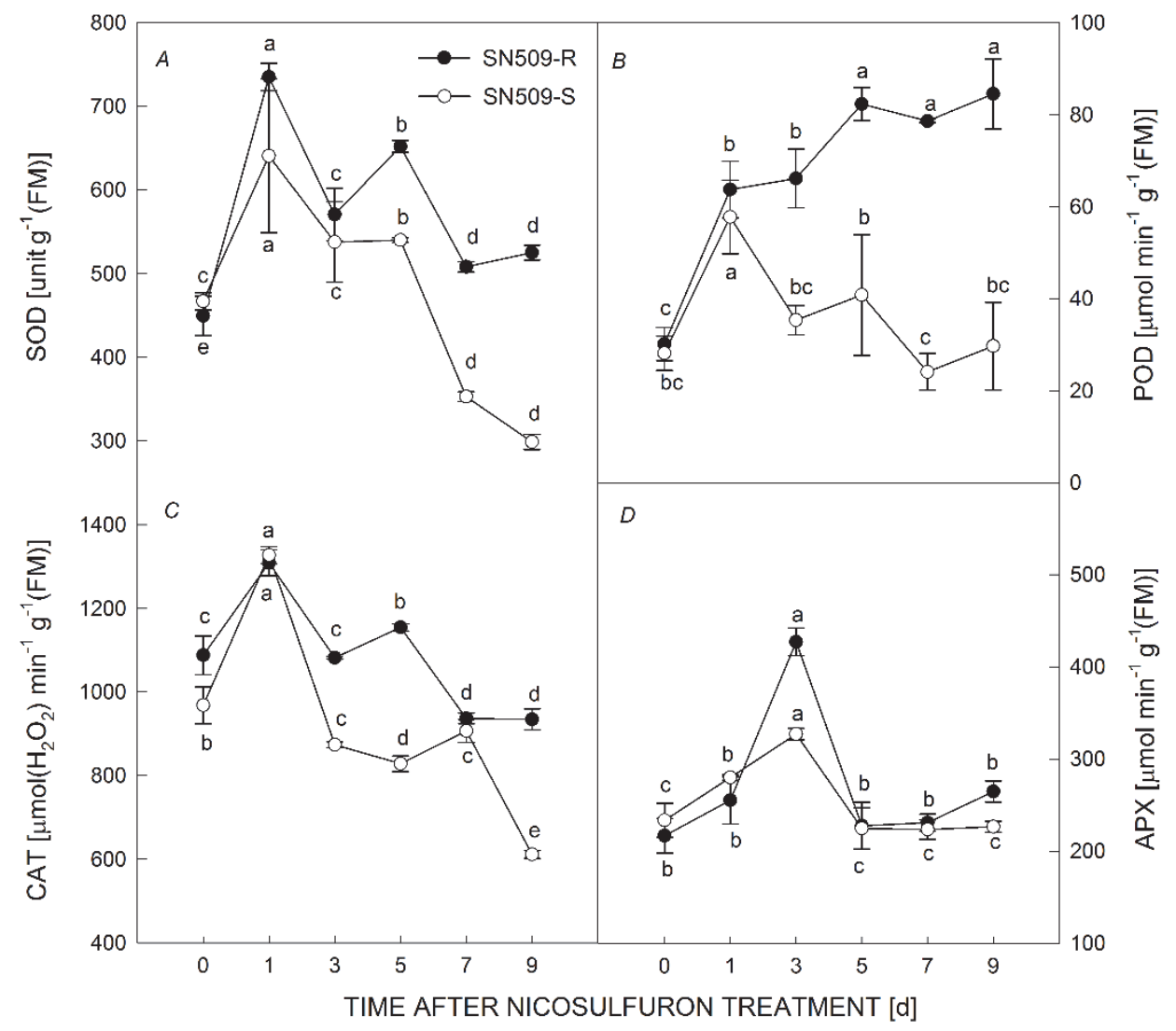

Fig. 3. Effects of nicosulfuron on superoxide dismutase (SOD; $A$ ), peroxidase (POD; $B$ ), catalase (CAT; $C$ ), and ascorbate peroxidase $($ APX; $D)$ in leaves of SN509-R and SN509-S. Vertical bars represent the SE $(n=5)$. Small letters indicate differences in values obtained on different days after nicosulfuron treatment $(P<0.05)$ according to a least significant difference (LSD) test.

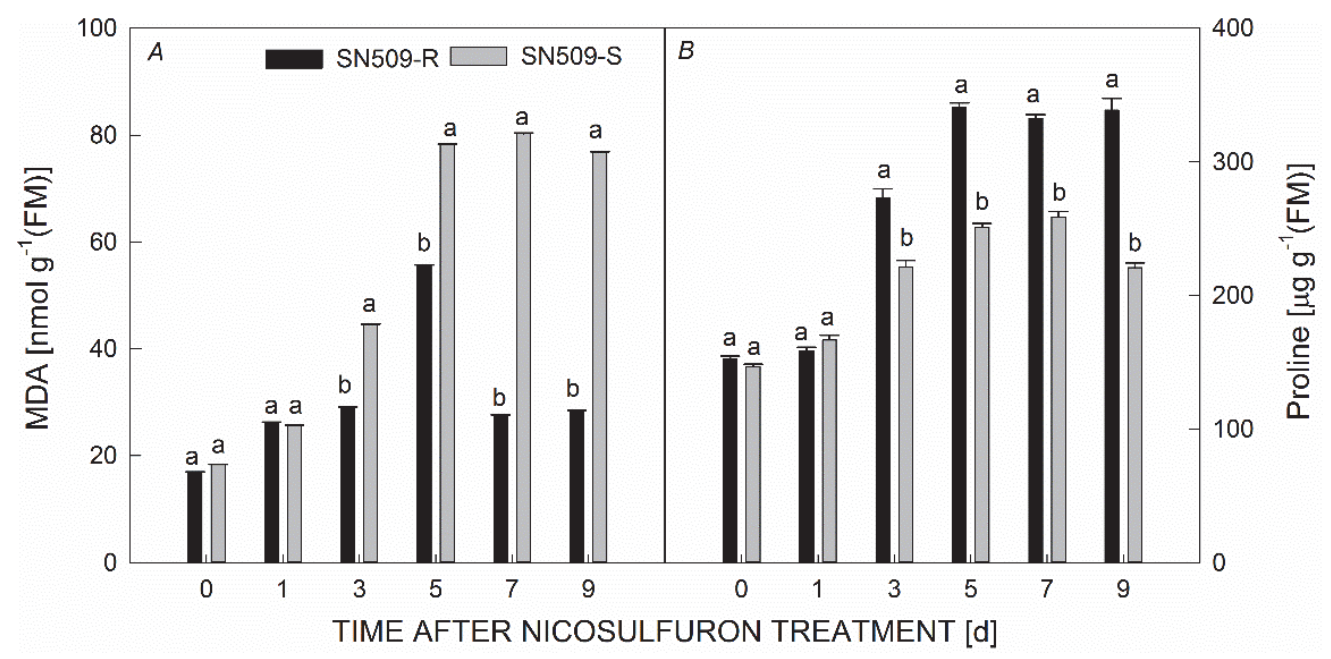

Fig. 4. Effects of nicosulfuron on the malondialdehyde content (MDA; $A$ ) and proline content $(B)$ in leaves of SN509-R and SN509-S. Vertical bars represent the SE $(n=5)$. Small letters indicate differences in values obtained on different days after nicosulfuron treatment $(P<0.05)$ according to a least significant difference (LSD) test.

on the leaves of SN509-S by nicosulfuron increased as the exposure time increased. A vital defense mechanisms in the leaves of SN509-R could protect plants from nicosulfuron damage. Based on our analysis, herbicide- resistance was associated with a high photosynthetic rate, ROS metabolism, and protective mechanisms. These are crucial physiological mechanisms underlying differences in nicosulfuron resistance between SN509-R and SN509-S. 
Conclusion: After spraying plants with nicosulfuron, $P_{\mathrm{N}}$, $E$, and $g_{\mathrm{s}}$ of SN509-S were lower than those of SN509-R. Compared to SN509-R, $\mathrm{F}_{\mathrm{v}} / \mathrm{F}_{\mathrm{m}}, \mathrm{q}_{\mathrm{P}}$, ETR, and $\Phi_{\mathrm{PSII}}$ significantly decreased in SN509-S, but NPQ significantly increased. Our study showed that activities of SOD, POD, CAT, and APX of SN509-S were significantly lower than

\section{References}

Aebi H.: Catalase in vitro. - Methods Enzymol. 105: 121-126, 1984.

Aroca R., Irigoyen J.J., Sánchez-Díaz M.: Photosynthetic characteristics and protective mechanisms against oxidative stress during chilling and subsequent recovery in two maize varieties differing in chilling sensitivity. - Plant Sci. 161: 719-726, 2001.

Belgers J.D.M., van Lieverloo R.J., van der Pas L.J.T. et al.: Effects of the herbicide 2,4-D on the growth of nine aquatic macrophytes. - Aquat. Bot. 86: 260-268, 2007.

Bigot A., Fontaine F., Clément C., Vaillant-Gaveau N.: Effect of the herbicide flumioxazin on photosynthetic performance of grapevine (Vitis vinifera L.). - Chemosphere 67: 1243-1251, 2007.

Cakmak I., Marschner H.: Magnesium deficiency and high light intensity enhance activities of superoxide dismutase, ascorbate peroxidase, and glutathione reductase in bean leaves. - Plant Physiol. 98: 1222-1227, 1992.

Debona D., Nascimento K.J.T., Gomes J.G.O. et al.: Physiological changes promoted by a strobilurin fungicide in the riceBipolaris oryzae interaction. - Pestic. Biochem. Phys. 130: 816, 2016.

Demmig B., Winter K., Krüger A., Czygan F.C.: Photoinhibition and zeaxanthin formation in intact leaves: A possible role of the xanthophyll cycle in the dissipation of excess light energy. - J. Plant Physiol. 84: 218-224, 1987.

Dobbels A.F., Kapusta G.: Postemergence weeds control in corn (Zea mays) with nicosulfuron combinations. - Weed Technol. 7: 844-850, 1993.

Eberline C.V., Rosow K.M., Geadelmann J.L., Openshaw S.J.: Differential tolerance of corn genotypes to DPX-M6316. Weed Sci. 37: 651-657, 1989.

Frankart C., Eullaffroy P., Vernet G.: Comparative effects of four herbicides on non-photochemical fluorescence quenching in Lemna minor. - Environ. Exp. Bot. 49: 159-168, 2003.

Freemark K., Boutin C.: Nontarget-plant risk assessment for pesticide registration. - Environ. Manage. 18: 841-854, 1994.

Genty B., Briantais J.M., Baker N.R.: The relationship between the quantum yield of photosynthetic electron transport and quenching of chlorophyll fluorescence. - Biochim. Biophys. Acta 990: 87-92, 1989.

Geoffroy L., Frankart C., Eullaffroy P.: Comparison of different physiological parameter responses in Lemna minor and Scenedesmus obliquus exposed to herbicide flumioxazin. Environ. Pollut. 131: 233-241, 2004.

Giannopolitis C.N., Ries S.K.: Superoxide dismutases: I. occurrence in higher plants. - Plant Physiol. 59: 309-314, 1977.

Govindjee: A role for a light-harvesting antenna complex of photosystem II in photoprotection. - Plant Cell 14: 1663-1668, 2002.

Hassan N.M., Nemat Alla M.M.: Oxidative stress in herbicidetreated broad bean and maize plants. - Acta Physiol. Plant. 27: 429-438, 2005. those of SN509-R. The higher amounts of ROS resulted in a reduction in $P_{\mathrm{N}}$, which might be associated with lower antioxidant enzyme activities. These results clarify the crucial physiological mechanisms explaining plant death in nicosulfuron-sensitive maize.

Heath R.L., Packer L.: Photoperoxidation in isolated chloroplasts. I. kinetics and stoichiometry of fatty acid peroxidation. - Arch. Biochem. Biophys. 125: 189-198, 1968.

Hu H.J., Shi Z.S., Lv X.L. et al.: [Effect of herbicide nicosulfuron on photosynthesis traits and chlorophyll fluorescence parameters of wax maize.] - J. Maize Sci. 22: 77-80, 2014. [In Chinese]

Hussain M.I., González L., Reigosa M.: Phytotoxic effects of allelochemicals and herbicides on photosynthesis, growth and carbon isotope discrimination in Lactuca sativa. - Allelopathy J. 26: 157-174, 2010.

Hwang H.J., Kim J.H., Eu Y.J. et al.: Photoinhibition of photosystem $\mathrm{I}$ is accelerated by dimethyldithiocarbamate, an inhibitor of superoxide dismutase, during light-chilling of spinach leaves. - J. Photoch. Photobio. B. 73: 79-85, 2004.

Jakob B., Heber U.: Photoproduction and detoxification of hydroxyl radicals in chloroplasts and leaves and relation to photoinactivation of photosystems I and II. - Plant Cell Physiol. 37: 629-635, 1996.

Jiang L., Yang H.: Prometryne-induced oxidative stress and impact on antioxidant enzymes in wheat. - Ecotox. Environ. Safe. 72: 1687-1693, 2009.

Jiang Z., Ma B.B., Erinle K.O. et al.: Enzymatic antioxidant defense in resistant plant: Pennisetum americanum (L.) K. Schum during long-term atrazine exposure. - Pestic. Biochem. Phys. 133: 59-66, 2016.

Kaňa R., Špundová M., Ilík P. et al.: Effect of herbicide clomazone on photosynthetic processes in primary barley (Hordeum vulgare L.) leaves. - Pestic. Biochem. Phys. 78: 161-170, 2004.

Kapusta G., Krausz R.F., Khan M., Matthews J.L.: Effect of nicosulfuron rate, adjuvant and weed size on annual weed control in corn (Zea mays). - Weed Technol. 8: 696-702, 1995.

Liu Z., Shi L., Bai L., Zhao K.: [Effects of salt stress on the contents of chlorophyll and organic solutes in Aeluropus littoralis var. sinensis Debeaux.] - J. Plant Physiol. Mol. Biol. 33: 165-172, 2007. [In Chinese]

Macedo R.S., Lombardi A.T., Omachi C.Y., Rörig L.R.: Effects of herbicide bentazon on growth and maximum quantum yield of photosystem II in the marine diatom skeletonema costatum. - Toxicol. in Vitro 22: 716-722, 2008.

Meyer M.D., Pataky J.K., Williams M.M.: Genetic factors influencing adverse effects of mesotrione and nicosulfuron on sweet corn yield. - Agron. J. 102: 1138-1145, 2010.

Murata N., Takahashi S., Nishiyama Y., Allakhverdiev S.I.: Photoinhibition of photosystem II under environmental stress. - BBA-Biochemistry 1767: 414-421, 2007.

Nakano Y., Asada K.: Hydrogen peroxide is scavenged by ascorbate-specific peroxidase in spinach chloroplasts. - Plant Cell Physiol. 22: 867-880, 1981.

Pataky J.K., Meyer J.D., Bollman J.D. et al.: Genetic basis for varied levels of injury to sweet corn hybrids from three cytochrome P450-metabolized herbicides. - J. Am. Soc. Hortic. Sci. 133: 438-447, 2008. 
Platiša J., Veljović-Jovanović S., Kukavica B. et al.: Induction of peroxidases and superoxide dismutases in transformed embryogenic calli of alfalfa (Medicago sativa L.). - J. Plant Physiol. 165: 895-900, 2008.

Qian H., Chen W., Sheng G.D. et al.: Effects of glufosinate on antioxidant enzymes, subcellular structure, and gene expression in the unicellular green alga Chlorella vulgaris. Aquat. Toxicol. 88: 301-307, 2008.

Ramel F., Sulmon C., Bogard M. et al.: Differential patterns of reactive oxygen species and antioxidative mechanisms during atrazine injury and sucrose-induced tolerance in Arabidopsis thaliana plantlets. - BMC Plant Biol. 9: 28, 2009.

Ray T.B.: Site of action of chlorsulfuron. - Plant Physiol. 75: 827-831, 1984.

Saladin G., Magné C., Clément C.: Impact of flumioxazin herbicide on growth and carbohydrate physiology in Vitis vinifera L. - Plant Cell Rep. 21: 821-827, 2003.

Sonoike K.: Degradation of $P s a B$ gene product, the reaction center subunit of photosystem I, is caused during photo inhibition of photosystem I: possible involvement of active oxygen species. - Plant Sci. 115: 157-164, 1996.

Stall W.M., Bewick T.A.: Sweet corn cultivars respond differentially to the herbicide nicosulfuron. - HortScience 27: 131-133, 1992.

Tan W., Li Q.L., Zhai H.: Photosynthesis and growth responses of grapevine to acetochlor and fluoroglycofen. - Pestic. Biochem. Phys. 103: 210-218, 2012.

Tarchoune I., Sgherri C., Izzo R. et al.: Antioxidative responses of Ocimum basilicum to sodium chloride or sodium sulphate salinization. - Plant Physiol. Bioch. 48 : 772-777, 2010.

Tjus S.E., Scheller H.V., Andersson B., Møller B.L.: Active oxygen produced during selective excitation of photosystem I is damaging not only to photosystem I, but also to photosystem II. - Plant Physiol. 125: 2007-2015, 2001.

van Kooten O., Snel J.F.H.: The use of chlorophyll fluorescence nomenclature in plant stress physiology. - Photosynth. Res. 25: 147-150, 1990.
Vass I., Styring S., Hundal T. et al.: Reversible and irreversible intermediates during photoinhibition of photosystem II: stable reduced $\mathrm{Q}_{\mathrm{A}}$ species promotes chlorophyll triplet formation. P. Natl. Acad. Sci. USA 89: 1408-1412, 1992.

Wang J., Zhong X.M., Lv X.L. et al.: [Advances in research on tolerance of differential corn cultivars to the nicosulfuron.] Chinese J. Pestic. Sci. 18: 282-290, 2016. [In Chinese]

Wang X.F., Guan C.H., Fan Z.W., Zhen H.J.: Application and development of sulfonylurea herbicides. - Agrochemicals 50: 9-15, 2011.

Williams B.J., Harvey R.G.: Effect of nicosulfuron timing on wild-proso millet (Panicum miliaceum) control in sweet corn (Zea mays). - Weed Technol. 14: 377-382, 2000.

Wu G.L., Cui J., Tao L., Yang H.: Fluroxypyr triggers oxidative damage by producing superoxide and hydrogen peroxide in rice (Oryza sativa). - Ecotoxicology 19: 124-132, 2010.

Wu X.X., Wu J.C., Jin G.Y. et al.: [Impact of herbicides on physiology and ecology of hydrophytes.] - Acta Ecol. Sin. 24: 2037-2042, 2004. [In Chinese]

Xue Y.J., Tao L., Yang Z.M.: Aluminum-induced cell wall peroxidase activity and lignin synthesis are differentially regulated by jasmonate and nitric oxide. - J. Agr. Food Chem. 56: 9676-9684, 2008.

Yoon J.Y., Shin J.S., Shin D.Y. et al:: Tolerance to paraquatmediated oxidative and environmental stresses in squash (Cucurbita spp.) leaves of various ages. - Pestic. Biochem. Physiol. 99: 65-76, 2011.

Yuan X.Y, Zhang L.G., Ning N. et al.: Photosynthetic physiological response of radix isatidis (Isatis indigotica Fort.) seedlings to nicosulfuron. - PLoS ONE 9: e105310, 2014.

Zheleva D., Tsonev T., Sergiev I., Karanov E.: Protective effect of exogenous polyamines against atrazine in pea plants. - J. Plant Growth Regul. 13: 203-211,1994.

Zhong X.M., Shi Z.S., Li F.H., Huang H.J.: Photosynthesis and chlorophyll fluorescence of infertile and fertile stalks of paired near-isogenic lines in maize (Zea mays L.) under shade conditions. - Photosynthetica 52: 597-603, 2014. 